\title{
A OBRA DE AUGUSTO TEIXEIRA DE FREITAS E A CONFORMAÇÃO DE UM DIREITO CIVIL TIPICAMENTE BRASILEIRO: sua genialidade compreendida como conciliação entre inovação sistemática e acuidade histórica ${ }^{1}$
}

\author{
THE WORK OF AUGUSTO TEIXEIRA DE FREITAS AND THE CONSTRUCTION OF A CIVIL LAW \\ TYPICALLY BRAZILIAN: his genius understood as conciliation between systematic innovation and historical \\ caution
}

Estevan Lo Ré Pousada

\begin{abstract}
Resumo:
O presente artigo tem por tema o papel desempenhado por Augusto Teixeira de Freitas no desenvolvimento de um Direito Civil tipicamente brasileiro; ao mesmo tempo em que contribuiu para o aprimoramento sistemático do Direito Civil vigente à época, serviu de elemento de conservação do conteúdo jurídico até então disciplinado pelas Ordenações Filipinas.
\end{abstract}

Palavras-chave: Augusto Teixeira de Freitas. Consolidação das Leis Civis. Esboço do Código Civil.

\begin{abstract}
:
The aim of this paper is to analyse the role played by Augusto Teixeira de Freitas in the development of a Civil Law typically Brazilian; his job has contributed to the systematic improvement of the Civil Law which was applied at his time (and at the same time has served as an element of conservation of the juridical content until the time disciplined by the Ordenações Filipinas).
\end{abstract}

Keywords: Augusto Teixeira de Freitas. Consolidação das Leis Civis. Esboço of the Civil Code.

Primeiro desafio àquele que pretende estudar algum dos meandros da obra de qualquer autor corresponde à delimitação do enfoque por meio do qual o trabalho haverá

\footnotetext{
1 Nota prévia: o presente artigo foi publicado originalmente a pretexto da coletânea organizada pelo prof. JeanFrançois Gerkens, da Universidade de Liège (Bélgica), publicada na RIDA 2004 com as seguintes referências respectivas: L'opera di Augusto Teixeira de Freitas e la conformazione di un diritto tipicamente brasiliano: il suo genio inteso come conciliazione tra innovazione sistematica e acuità storica in Revue Internationale des Droits de l'Antiquitè, n. 51, p. 187-196, 2004. Trata-se de estudo publicado por ocasião do início de uma pesquisa que redundou em nossa dissertação de Mestrado. Assim, trata-se de trabalho sintético cuja finalidade foi simplesmente a de proporcionar a divulgação de nossa pesquisa no âmbito acadêmico. Pela coletânea dos resultados obtidos ao longo do desenvolvimento de nossos estudos, cf. POUSADA, Estevan Lo Ré. Preservação da Tradição Jurídica Luso-Brasileira: Teixeira de Freitas e a introdução à Consolidação das Leis Civis. 2006. 263 p. Dissertação (Mestrado) - Faculdade de Direito, Universidade de São Paulo, São Paulo.

2 Mestre e Doutor em Direito Civil pela Faculdade de Direito da Universidade de São Paulo; Professor da Fundação Escola de Comércio Álvares Penteado; Professor do Centro de Extensão Universitária (CEU); Professor da Coordenadoria Geral de Especialização, Aperfeiçoamento e Extensão da Pontifícia Universidade Católica de São Paulo - CoGEAE - PUC/SP; e-mail: pousada@usp.br.
} 
de ser conduzido. Em verdade, nosso principal objetivo é o de discutir a influência da obra de Augusto Teixeira de Freitas na formação do moderno Direito Privado brasileiro. Só que o modo, segundo o qual tal objetivo há de ser atingido, deve ser esclarecido de antemão.

Sem qualquer sombra de dúvida, para muitos o presente tema corresponderia a um mote de estudo extremamente feliz. Isso, de fato, se nos pareceu da mesma forma, em um primeiro momento. Apenas em um primeiro momento.

A obra de Augusto Teixeira de Freitas corresponde a um terreno verdadeiramente desconhecido à maioria dos juristas brasileiros. ${ }^{3}$ Seja em virtude da nãoobrigatoriedade do estudo da História do Direito junto aos cursos de graduação brasileiros, seja mesmo face ao completo desapego manifestado ao longo dos tempos pelo brasileiro em relação à sua história, uma plêiade de fatores acaba por acarretar um completo desapreço pelos estudos históricos na área jurídica.

A atestar a ignorância da maior parte de nossos juristas acerca da obra de Augusto Teixeira de Freitas, José Gomes Bezerra Câmara enuncia - a pretexto do comentário à Tábua Sintética aprovada por Zacarias de Góes e Vasconcelos em 23 de julho de 1864: “(n)essa Tábua Sintética mantém ele a genérica divisão dos direitos em pessoais e reais, entre êstes incluindo a posse. Contudo, nas suas linhas gerais, não se afasta das idéias mestras já anteriormente consagradas na Introdução, de que, aliás, nunca se afastou. Isso vem confirmar a maturidade, a meditação, o estudo profundo dos quais resultou aquela classificação genial, infelizmente ignorada ainda tantos anos decorridos". ${ }^{4}$

A despeito de tal estado de coisas, quem já se debruçou sobre a imensa obra de Augusto Teixeira de Freitas - imensidão não tanto devida à extensão, mas principalmente à densidade de seus estudos - pode seguramente asseverar a amplitude exagerada da pretensão acima formulada. Postas tais considerações, há que se mencionar - de passagem, ao menos por enquanto - o espírito dicotômico ${ }^{5}$ que perpassa a obra de

\footnotetext{
3 Não-obstante a escassez de estudos a respeito de tão importante personalidade do direito brasileiro, não se pode deixar de fazer referência ao Congresso internazionale del centenario di Augusto Teixeira de Freitas, realizado em Roma, entre os dias 12 e 14 de dezembro de 1983, cujas atas foram publicadas sob a coordenação do romanista Sandro SCHIPANI. A respeito, cf. SCHIPANI, Sandro. Augusto Teixeira de Freitas e il diritto latinoamericano. Padova: CEDAM, 1988.

4 CÂMARA, José Gomes Bezerra. Subsídios para a história do direito pátrio. Rio de Janeiro: Livraria Brasiliana Editora, 1966. v. 3, p. 146

5 Sobre a importância das classificações e das dicotomias para a obra de Augusto Teixeira de Freitas, cf. PEREIRA, Aloysio Ferraz. O uso brasileiro do direito romano no século XIX. Papel de Teixeira de Freitas in SCHIPANI, Sandro. Augusto Teixeira de Freitas e il diritto latinoamericano. Padova: CEDAM, 1988. p. 94-99.
} 
Augusto Teixeira de Freitas. Diria o Autor - como de fato o fez, em 1867 - que "sem definir, sem distinguir, sem dividir, nunca me foi possível formular a parte imperativa das matérias; e sempre, ante mim erguido, o aforismo do perigo das definições acusava-me de uma falta, e com ele o preceito dos mestres, preceito, que infelizmente ainda ninguém soube guardar!"'.

A respeito da importância das divisões e classificações no delineamento do pensamento jurídico de Teixeira de Freitas, oportuna a lembrança de Nelson Saldanha: "(a) famosa frase sobre $0<<$ perigo $>>$ das definições, que aliás teve em conta expressamente mais de uma vez, jamais inibiu o autor da Consolidação de definir; como jamais o inibiu de classificar. Definir e classificar, formas dominantes do racionalismo ocidental clássico (desde Descartes e Domat, desde Spinoza e Cuvier), eram ainda para Freitas o modus operandi por excelência do saber jurídico". ${ }^{7}$

Ou, nas palavras do próprio Autor, contidas na sua Nova Apostila:

sem divisões e classificações não há sistema de conhecimentos. Em dividir está o grande recurso de nossa débil inteligência, sem o qual a observação e a comparação seriam impossíveis e a memória sucumbiria ao peso de um prodigioso número de idéias. ${ }^{8}$

Ao que acrescentaríamos, sem qualquer receio - em relação à sua obra em particular - que sem "bipartir", nenhum conhecimento poderá ser haurido da mesma. Isto posto, natural seria o desenvolvimento de um esforço pela diagnose de alguma das dicotomias discutidas pelo Autor em texto, e decerto já se teria aí um belíssimo trabalho encampado. "Direito Civil e Direito Comercial sob a perspectiva de Teixeira de Freitas"; ou mesmo "direito material e direito processual face aos comentários sobre o Código

\footnotetext{
${ }^{6}$ Carta de Augusto Teixeira de Freitas, de 20 de setembro de 1867, dirigida ao ministro e secretário de Estado dos Negócios da Justiça, conselheiro Martim Francisco Ribeiro de Andrada. A justificar a importância da elaboração de um Código Geral, no qual estariam contidas as definições a serem utilizadas pelos juristas em suas atividades quotidianas, com efeito, o Autor faz menção ao qüinqüagésimo livro do Digesto, de diversis regulis iuris antiqui, mais especificamente à Lei n. 202 (D.50, 17, 202): "202. Javolenus. Omnis definitio in jure civili periculosa est: parum est enim, ut non subverti possit” (202. Javoleno. Toda definição, em Direito Civil, é perigosa; poucas, com efeito, não podem ser modificadas).

Por oportuno, de se ressaltar que a idéia de um Código Geral tem, pois, suas origens nos dois últimos títulos do Digesto - de verborum significatione e de diversis regulis iuris antiqui - como já fora destacado pelo próprio Pothier, consoante nos informa Teixeira de Freitas no corpo da carta ora referida.

7 SALDANHA, Nelson. História e sistema em Teixeira de Freitas. In: SCHIPANI, Sandro. Augusto Teixeira de Freitas e il diritto latinoamericano. Padova: CEDAM, 1988. p. 70.

8 FREITAS, Augusto Teixeira de. Nova apostilla à censura do senhor Alberto de Moraes Carvalho sobre o Projecto do Código civil portuguez. Rio de Janeiro: Typographia Universal de Laemmert, 1859. p. 52.
} 
Seabra"; ou ainda, o mais pretensioso de todos os estudos, "direitos pessoais e direitos reais em Teixeira de Freitas". Podemos asseverar, com a mais absoluta certeza, que até o presente momento, todos os temas acima referidos não se encontram nem de longe exauridos. No entanto, queremos menos... e muito mais!

Queremos menos, pois não pretendemos, em uma simples comunicação de poucos minutos, a originalidade que se hauriria de um estudo de tamanha envergadura. Nossa pretensão é bastante mais modesta: apenas a de chamar a atenção para o fio condutor que perpassa dois momentos específicos da obra de Augusto Teixeira de Freitas: a Introdução à Consolidação das Leis Civis e a carta dirigida ao ministro da Justiça, conselheiro Martim Francisco Ribeiro de Andrada, de 20 de setembro de 1867.

Queremos mais, conforme dito. Aquele que já se debruçou sobre a obra de Teixeira de Freitas sabe que neste simples diagnóstico se encontra um dos mais preciosos tesouros até o presente momento guardados pela historiografia jurídica brasileira.

Nossa pretensão já seria bastante grande em tencionar a delimitação desse "simples" fio condutor. Mas cremos indispensável contextualizá-lo, ${ }^{9}$ sob pena de percebermos tão-somente uma análise comparativa completamente desprovida de significação histórica. Isto porque nos parece extremamente importante esclarecer em que contexto histórico tal objeto de estudo se insere.

Com efeito, a Consolidação das Leis Civis deve ser tomada no seu imprescindível contexto histórico-jurídico, qual seja, o de instrumento apto a intermediar a transição da disciplina civil decorrente do Livro IV das Ordenações Filipinas (1603) e a promulgação do Código Civil brasileiro - o que só se daria em 1916. De fato, antes mesmo da outorga da Constituição Imperial (1824) - a qual por meio de seu art. 179, XVIII determinava fosse promulgado em breve um Código Penal e um Código Civil, fundados ambos nas sólidas bases da justiça e da eqüidade - a lei de 20 de outubro de 1823 já estabeleceu o regime de transição da disciplina civil com a Proclamação da Independência (1822): as Ordenações, Leis, Regimentos, Alvarás, Decretos e Resoluções promulgados pelos Reis de Portugal até 25 de abril de 1821 permaneceriam em vigor no Brasil, sendo que, a partir daquela data, somente vigorariam no ordenamento jurídico brasileiro os diplomas promulgados pelo príncipe regente e posteriormente imperador constitucional

\footnotetext{
9 De fato, é com a aprovação da Consolidação das Leis Civis - mediante Aviso de 24 de dezembro de 1858 após parecer favorável da Comissão encarregada de rever e examinar a obra - que pela primeira vez se pode vislumbrar a existência de uma obra legislativa de porte, em matéria civil, de índole nacional. Contudo, tal análise será levada a curso logo mais à frente. De qualquer forma, por um panorama da importância da própria Lei de 20 de outubro de 1823, cf. ALMEIDA, Cândido Mendes. Código Philippino ou Ordenações e Leis no Reino de Portugal recopiladas por mandado d'El-Rey D. Philippe I. 14. ed. Rio de Janeiro: Typographia do Instituto Philomathico, 1870. p. LXXV.
} 
D. Pedro de Alcântara; tudo isso, enquanto não fosse organizado um novo código, ou não fossem especialmente alteradas.

Mais ainda, cumpre destacar a importância da Introdução à Consolidação das Leis Civis na formação do Direito Privado brasileiro. Nas palavras de um dos maiores historiadores do Direito luso-brasileiro, Guilherme Braga da Cruz,

(g)oradas as tentativas da Segunda metade do século XIX para a feitura dum Código Civil, a Consolidação de Teixeira de Freitas fícou a ser, até começos do século XX, a expressão mais autorizada do direito vigente no Brasil. Respeitada como um verdadeiro código, ela conseguiu impor, na jurisprudência e na doutrina, o prestígio da corrente conservadora, fazendo cair em desgraça, duma vez para sempre, várias inovações preconizadas pela corrente progressista, que o direito brasileiro, ao contrário do direito português, jamais aceitaria. ${ }^{10}$

Se se lograsse êxito quanto à exploração dos três objetos de análise acima mencionados - a comparação entre os sistemas pretendidos na Introdução à Consolidação das Leis Civis e aquele vertido na Carta de 1867; a contextualização da Consolidação das Leis Civis no panorama da formação do Direito Privado brasileiro; e, por fim, o esclarecimento do legado do sistema idealizado na Introdução à formação do moderno Direito Privado brasileiro - poderia-se enfim encetar um esforço final: uma vez comprovada a influência do sistema do Autor, a análise seria encerrada com considerações acerca do conteúdo da Consolidação das Leis Civis, e a justificativa de sua importância no contexto histórico-jurídico de sua aprovação. ${ }^{11}$

Justifiquemo-nos. A abordagem aludida, por meio das três linhas delineadas há pouco, renderia: em primeiro lugar, um enfoque estrutural da obra de Teixeira de Freitas,

${ }^{10}$ Cf. CRUZ, Guilherme Braga da. Formação histórica do moderno Direito Privado português e brasileiro. In: OBRAS Esparsas II. Estudos de história do direito: direito moderno - $1^{\text {a }}$ parte. Coimbra: Imprensa da Universidade, p. 65-66.

${ }^{11}$ Por oportuno, ressalta Aloysio Ferraz Pereira a importância do Direito Romano na formação do moderno Direito Privado brasileiro, por intermédio da atuação de Teixeira de Freitas, quando elucida que "(s)e a presença do Direito Romano é menos visível na sua exposição da fundamental questão do método, porque se apresenta quase desacompanhada de citações de fontes e autores, essa influência the é mais efetiva e generalizada ainda que a utilização substantiva das soluções romanas, porque é aquele direito que the fornece os modelos e as inumeráveis ocasiões para exercer a sua reflexão de jurista filósofo e se adestrar nas subtilesas da dialética, próprias do intérprete e do legislador (...) é a partir de princípios metodológicos e ontológicos , que firmemente estabelece como filósofo, que ele vai poder julgar os contemporâneos, os modernos, a tradição intermédia e os romanos, a fim de explorar e utilizar, com livre espírito crítico, os resultados desse milenar trabalho de jurisprudência" (PEREIRA, Aloysio Ferraz. O uso brasileiro do Direito Romano no século XIX. Papel de Teixeira de Freitas. In: SCHIPANI, Sandro. Augusto Teixeira de Freitas e il diritto latinoamericano. Padova: CEDAM, 1988. p. 96). 
fazendo com que nos salte aos olhos os pesados e bem articulados andaimes em que se funda todo o edifício constituído ao longo de sua atuação; em um segundo momento, uma vista do ambiente, no qual se insere a obra levada a efeito; finalmente, em decorrência do terceiro aspecto, sua importância como modelo na formação dos subseqüentes projetos de codificação civil nacionais. Contudo, a se encerrar aí o trabalho empreendido, teremos um esforço tão incompleto como os, até o presente momento, despendidos. Necessário evidenciar ainda de que modo o sistema, uma vez embebido de conteúdo bastante específico, constitui-se no instrumento decisivo de preservação da tradição jurídica lusobrasileira.

Seremos obviamente indagados sobre a oportunidade de um tal influxo, de tal modo distanciado daquele originalmente concebido. Por qual razão considerar o conteúdo da Consolidação das Leis Civis, se foi dito acima que o objeto de nosso trabalho é a forma, o modelo adotado por Teixeira de Freitas e que será legado ao legislador de 1916 - e mesmo de 2002? A importância - uma vez estudada, ainda que superficialmente, a obra de Teixeira de Freitas - reside no fato de que a concatenação dos dois aspectos comprova a singularidade de Teixeira de Freitas no panorama histórico-jurídico brasileiro. Inovação quanto à estrutura, cautela e acuidade histórica quanto ao conteúdo.

Em uma expressão, sensibilidade. Essa a razão para a necessidade de dois códigos, referida na Carta, de 20 de setembro de 1867. O código geral, destinado aos estudiosos (aos versados na matéria jurídica) contendo definições consubstanciadoras das verdades jurídicas, essenciais e imutáveis; e o Código Civil, voltado ao povo, ou por tal razão essencialmente histórico e contingente.

Uma constatação tão-evidente, e que nos parece ter ficado descurada ao longo de tantos anos. Inúmeros estudos existem em que se alude à genialidade de Teixeira de Freitas. Mas nenhuma linha sobre a relevância da "bipartição" do movimento codificador civil brasileiro no contexto em que se insere o pensamento jurídico de Augusto Teixeira de Freitas.

A sua tão-aclamada genialidade, ${ }^{12}$ que até o presente momento resta em grande parte incompreendida, ao menos ao Autor destas linhas - tal qual expressa em seus

\footnotetext{
12 Apenas a título exemplificativo, destaque-se a assertiva de Nelson Saldanha: “(a) $<<$ genialidade $>>$, que tantos tem apontado em sua obra, correspondeu a esta visão $<<$ orgânica $>>$ que possuiu para a imagem do direito legislado como um todo - não apenas do Direito Civil - em época onde ainda não se dispunha do conceito de ordenamento" (SALDANHA, Nelson. História e sistema em Teixeira de Freitas. In: SCHIPANI, Sandro. Augusto Teixeira de Freitas e il diritto latinoamericano. Padova: CEDAM, 1988. p. 61).

Se do ponto de vista dogmático não há como descurar de tal observação, do ponto de vista histórico, a nosso ver, tal fator perde relevância, principalmente quando se tem em mente a Reformação do Direito Administrativo levada a curso por Paschoal José de Mello Freire dos Reis - e tentada quanto ao Direito
} 
moldes tradicionais. Poder-se-ia dizer que a constatação acima promovida se encontra implícita em todos os estudos até o momento produzidos. Momento, pois, de torná-la evidente, clara, cristalina.

Embebido num romanismo que lhe custou por vezes grandes dissabores ${ }^{13}-\mathrm{e}$ aqui cabe alusão à polêmica havida com Caetano Alberto Soares -, conseguiu ser autêntico exemplo da "pandectística" nacional; em tamanhas proporções, talvez o único. Depurou, à moda savigyana, conceitos jurídicos tão importantes como o de atos jurídicos que não são negócios jurídicos - resultado a que o próprio Savigny não chegou. Como observa José Carlos Moreira Alves:

(e)m dois pontos se adiantava Freitas a Savigny: primeiro, porque este, ao aludir aos atos jurídicos que não eram negócios jurídicos, enquadrava neles atos lícitos e atos ilícitos; segundo, porque, enquanto Savigny apenas fazia a distinção, Freitas ressaltava claramente que os efeitos desses atos lícitos seriam somente os previstos na lei, o que só veio a ser evidenciado pela doutrina mais moderna, a partir do início do século XX, com Manigk, ao basear a distinção entre negócios jurídicos e participações de vontade na diferença entre efeitos ex voluntate e efeitos ex lege. Ë admirável, no plano estrito do legislador, a intuição de Freitas em incluir no Esboço esse art. 436. Só recentemente, em 1967, é que o novo Código Civil português veio a ocupar-se deles, preocupando-se, porém, apenas a alertar que a tais atos são aplicáveis, na medida em que a analogia das situações o justifique, as normas do negócio jurídico. ${ }^{14}$

Foi responsável, contudo, pela preservação das tradições jurídicas tipicamente luso-brasileiras. Um exemplo, pois, bastante elucidativo: muitos os que atualmente bradam aos quatro ventos a distinção entre o contrato de mandato e o negócio

Penal. Já se pode entrever, em tais episódios, tentativas de sistematização jurídica - isso para não se aludir às próprias Ordenações Afonsinas, Manuelinas e Filipinas, quanto à divisão por livros ou às Decretais de Gregório IX. A respeito, cf. ALMEIDA, Cândido Mendes. Código Philippino ou Ordenações e Leis no Reino de Portugal recopiladas por mandado d'El-Rey D. Philippe I. 14. ed. Rio de Janeiro: Typographia do Instituto Philomathico, 1870. p. V-XXXVII.

13 Não se pode deixar de mencionar, neste ponto, assunto que será retomado mais adiante, concernente à renúncia de Teixeira de Freitas à Presidência do Instituto dos Advogados Brasileiros, quando sustentou que os filhos de escrava manumitida pela via testamentária, sob condição eram escravos do herdeiro assim como sua mãe. Sobre o episódio - não-obstante retomada posterior do tema - cf. ALVES, José Carlos Moreira. A formação romanística de Teixeira de Freitas e seu espírito inovador. In: SCHIPANI, Sandro. Augusto Teixeira de Freitas e il diritto latinoamericano. Padova: CEDAM, 1988. p. 19-20; MEIRA, Sílvio Augusto de Bastos. Teixeira de Freitas: o jurisconsulto do Império: vida e obra. 2. ed. Brasília: Cegraf, 1983. p. 73-87.

${ }^{14}$ Cf. ALVES, José Carlos Moreira. Panorama do direito civil brasileiro: das origens aos dias atuais. Revista da Faculdade de Direito da Universidade de São Paulo, São Paulo, v. 88, p. 200-201, 1993. 
jurídico unilateral de representação não atentam para o fato de que a manutenção da natureza, essencialmente representativa do contrato de mandato foi promovida de modo consciente por um dos maiores romanistas que o País conheceu, na disciplina articulada entre os arts. 456 e 476 da Consolidação das Leis Civis.

Teixeira de Freitas não desconhecia seja o Direito Romano, seja mesmo o Direito moderno das nações civilizadas - tal qual preceituado pela Lei da Boa Razão, de 18 de agosto de 1769, e pelos Novos Estatutos da Universidade de Coimbra, de 1772, sendo que Guilherme Braga da Cruz é categórico ao afirmar que:

(n)ão é, de resto, note-se bem, por espírito retrógrado ou por deficiente conhecimento das mais modernas codificações e obras doutrinárias, que Teixeira de Freitas se mostra ardentemente conservador, mas com base numa sólida preparação científica, que reiteradas vezes põe à prova, ao discutir certas orientações inovadoras e ao expor as razões por que prefere, contra elas, as soluções tradicionais. Nem, aliás, o seu espírito conservador é tão intransigente, que não dê guarida, uma vez que outra, a alguma interpretação mais arrojada, ou a alguma inovação merecedora de ser acolhida por via integrativa. ${ }^{15}$

Por tal razão, discordamos, em parte, daqueles que nos últimos tempos tratam do espírito criador de Augusto Teixeira de Freitas, deitando aí a sua genialidade; francamente nos parecem, ao menos, precipitados. A singularidade da obra de Teixeira de Freitas está em seu espírito conciliador. Conciliador de uma cientificidade e um espírito de criatividade ímpar quanto ao sistema; ao mesmo passo guardião ferrenho da tradição jurídica nacional, quanto ao fundo que disciplina a vida do povo, o cotidiano de uma massa em sua maior parte desconhecedora do ordenamento jurídico que a rege. ${ }^{16}$

${ }^{15}$ Cf. CRUZ, Guilherme Braga da. Formação histórica do moderno direito privado português e brasileiro. In: OBRAS Esparsas II. Estudos de história do direito: direito moderno. 1. parte. Coimbra: Imprensa da Universidade. p. 65.

De sua parte, o conhecimento das modernas codificações em nada ilidia a formação profundamente romanística de Teixeira de Freitas: "(o) código civil francês, bem como os demais códigos, não são senão a acomodação escrita do Direito Romano à civilização moderna. A decretação desses códigos tirou, é certo, ao Direito Romano a autoridade externa da lei, mas sem embargo ele conserva uma autoridade talvez maior - continua a ser a substância, a regra, o molde do pensamento jurídico moderno" (PEREIRA, Aloysio Ferraz. op. cit., p. 90-91).

${ }^{16}$ A propósito, em relatório encaminhado pelo ministro e secretário de Estado dos Negócios da Justiça à Assembléia Nacional Legislativa, de 15 de maio de 1869, se insiste, pois, nas idéias de que "a lei política e civil deve estar ao alcance de todos"; "a forma popular da legislação, aquela que rompe o monopólio da ciência e concorre para vulgarizar o direito escrito é sem dúvida o código"; e por fim, de que "um código civil não é obra da ciência e do talento unicamente; é sobretudo obra dos costumes, das tradições, em uma palavra, da civilização brilhante ou modesta de um povo" (cf. CARVALHO, Orlando de. Teixeira de Freitas e a unificação 
Neste sentido, Guilherme Braga da Cruz destaca que

(o) caráter conservador da Consolidação obedecia, antes de mais nada, às próprias instruções dadas pelo Governo Brasileiro ao seu autor (...) (m)as o conservantismo da ordem governamental vinha ao encontro da própria maneira de pensar de Teixeira de Freitas. No extenso prefácio de sua obra, critica severamente o abuso, a que tantos juristas se tinham acostumado, de se desviar, sem grandes escrúpulos, dos textos legislativos vigentes. ${ }^{17}$

E a tal propósito dispara Teixeira de Freitas, em nota de rodapé ao art. 36 do célebre Esboço, que

(a)s leis são feitas para o homem, e não o homem para as leis. O homem é o ente inteligente e livre, e não uma tabula rasa em que o legislador constrói codificações arbitrárias. ${ }^{18}$

De modo que, sem dúvida alguma, temos o Autor como verdadeiro gênio. Mas não nos moldes tradicionais, em que se tornou lugar comum aludir ao espírito conservador do Teixeira de Freitas da Consolidação e ao incontido afã criativo do Autor do Esboço. Definitivamente acreditamos que não. E é na Carta, de 20 de setembro de 1867, que encontraremos a chave para a compreensão do modo pelo qual se pode entrever inovação e conservação tanto na Consolidação quanto no Esboço. É a separação entre estrutura e repertório normativo, entre Teoria Geral do Direito e Dogmática Jurídica que definitivamente faz de Teixeira de Freitas um legítimo representante do usus modernus pandectarum em terras brasileiras. Como já dito, talvez o único que esta terra conheceu nos parâmetros por ele atingidos. Esta, enfim, a sua singularidade, a nosso modesto ver. E na correção de rumos acima proclamada, tentaremos nos desvencilhar, em breve, dos obstáculos que decerto despontarão neste caminho que ora se inicia.

Angra dos Reis, setembro de 2004

do direito privado. In: SCHIPANI, Sandro. Augusto Teixeira de Freitas e il diritto latinoamericano. Padova: CEDAM, 1988. p. 103).

${ }^{17}$ Cf. CRUZ, Guilherme Braga da. op. cit., p. 64.

${ }^{18}$ FREITAS, Augusto Teixeira de. Esboço. Rio de Janeiro: Ministério da Justiça, 1952. p. 39-40. 
Referências

ALMEIDA, Cândido Mendes. Código Philippino ou Ordenações e Leis no Reino de Portugal recopiladas por mandado d'El-Rey D. Philippe I. 14. ed. Rio de Janeiro: Typographia do Instituto Philomathico, 1870.

ALVES, José Carlos Moreira. A formação romanística de Teixeira de Freitas e seu espírito inovador. In: SCHIPANI, Sandro. Augusto Teixeira de Freitas e il diritto latinoamericano. Padova: CEDAM, 1988.

. Panorama do direito civil brasileiro: das origens aos dias atuais. Revista da Faculdade de Direito da Universidade de São Paulo, São Paulo, v. 88, p. 200-201, jan./dez.1993.

CRUZ, Guilherme Braga da. Formação histórica do moderno direito privado português e brasileiro. In: OBRAS Esparsas II. Estudos de história do direito: direito moderno. 1. parte. Coimbra: Imprensa da Universidade.

CÂMARA, José Gomes Bezerra. Subsídios para a história do direito pátrio. Rio de Janeiro: Livraria Brasiliana Editora, 1966. v. 3.

CARVALHO, Orlando de. Teixeira de Freitas e a unificação do direito privado. In: SCHIPANI, Sandro. Augusto Teixeira de Freitas e il diritto latinoamericano. Padova: CEDAM, 1988.

FREITAS, Augusto Teixeira de. Esboço. Rio de Janeiro: Ministério da Justiça, 1952.

. Nova apostilla à censura do senhor Alberto de Moraes Carvalho sobre o projecto do código civil portuguez. Rio de Janeiro: Typographia Universal de Laemmert, 1859.

MEIRA, Sílvio Augusto de Bastos. Teixeira de Freitas: o jurisconsulto do império - vida e obra. 2. ed. Brasília: Cegraf, 1983.

PEREIRA, Aloysio Ferraz. O uso brasileiro do direito romano no século XIX. Papel de Teixeira de Freitas. In: SCHIPANI, Sandro. Augusto Teixeira de Freitas e il diritto latinoamericano. Padova: CEDAM, 1988.

SALDANHA, Nelson. História e sistema em Teixeira de Freitas. In: SCHIPANI, Sandro. Augusto Teixeira de Freitas e il diritto latinoamericano. Padova: CEDAM, 1988.

SCHIPANI, Sandro. Augusto Teixeira de Freitas e il diritto latinoamericano. Padova: CEDAM, 1988. 